\title{
Microstructural Evolution of a Heterogeneous Austenitic Stainless Steel Processed by Equal Channel Angular Sheet Extrusion (ECASE).
}

\author{
J. A. Muñoz ${ }^{1}$, V. Tartalini ${ }^{1}$, P. Risso ${ }^{1}$, M. Avalos ${ }^{1}$, R. E. Bolmaro ${ }^{1 *}$ \\ 1. Instituto de Física Rosario, Consejo Nacional de Investigaciones Científicas y Técnicas- \\ CONICET, Universidad Nacional de Rosario, Ocampo y Esmeralda, 2000 Rosario, Argentina. \\ *Corresponding author: bolmaro@ifir-conicet.gov.ar
}

Stainless steels stand out for their excellent properties such as corrosion resistance, high temperature resistance and good formability among others [1-4]. From a mechanical point of view, austenitic stainless steels are materials that attract attention due to their wide mechanical strength range that can be achieved mainly due to the deformation induced phase transformation phenomenon, from austenite fcc to martensite bcc [5-7]. In this study, an austenitic stainless steel $(\leq 0.03 \mathrm{C} ; 18-20 \mathrm{Cr} ; 69.9-74 \%$ $\mathrm{Fe} ; \leq 2 \mathrm{Mn} ; 8-12 \mathrm{Ni} ; \leq 0.045 \mathrm{P} ; \leq 1 \mathrm{Si} ; \leq 0.03 \mathrm{~S}(\mathrm{wt} \%)$ ) in the form of Sheet $(20 \mathrm{~mm}$ wide and $5 \mathrm{~mm}$ thick) was processed by 1 ECASE pass at room temperature using a matrix with an inner channel angle of $\Phi$ $=150^{\circ}$ (see Figure 1). Before processing the material, a heat treatment was carried out at $850^{\circ} \mathrm{C}$ for $2 \mathrm{~h}$ and subsequent water quenching. The microstructure characterization was carried out by electron backscattered diffraction (EBSD). Samples were cut from the transversal direction (TD) plane and prepared by mechanical polishing until colloidal silica suspension with a particle size of $0.02 \mu \mathrm{m}$. The data was processed with TSL OIM $7.3 \mathrm{~b}$ software. The software processing parameters were: Maximum misorientation threshold of $5^{\circ}$ to calculate grain size and a cleaning subroutine to remove unindexed points using the grain dilation method taking into account a minimum size of 4 points. After ECASE processing, it was found that greater deformations were introduced around the sheet edges, while the middle area remained less affected by the deformation. The greater deformations at the edges caused a greater transformation from austenite to martensite, resulting in a heterogeneous structure along the sheet thickness, as shown in Figure 1.

Tensile tests revealed that after the deformation process, the material increased its yield strength almost 3 times from $200 \mathrm{MPa}$ in its initial state to $600 \mathrm{MPa}$. In Figure 2a it can be seen that tensile tests in different areas of the sheet thickness revealed a heterogeneous behavior with tougher and less ductile areas (greater amount of bcc martensite) and other more ductile but softer areas (greater amount of austenite). The main objective of this research is the study of mechanical and microstructural properties of a heterogeneous structure in an austenitic stainless steel deformed by ECASE maintaining a good strength-ductility ratio. The heterogeneous structure obtained consists mainly of a more pronounced phase change in the sheet edges vicinity than the middle zone, as well as a greater Geometrically Necessary Dislocations (GND) density at the edges than the middle zone (see Figure 2b). For this reason, through mechanical tests and microstructural characterization, the ductility and strength contributions of each of these areas to the heterogeneous material was studied.

\section{References}

[1] J. Li et al., J. Mater. Sci. 53 (2018) 10442-10456.

[2] G.S. Sun et al., Mater. Charact. 110 (2015) 228-235.

[3] S. Qu et al., Mater. Sci. Eng. A 475 (2008) 207-216.

[4] F.K. Yan, G.Z. Liu, N.R. Tao, K. Lu, Acta Mater. 60 (2012) 1059-1071

[5] Y. He et al., Mater. Sci. Eng. A 739 (2019) 343-347.

[6] M. Naghizadeh, H. Mirzadeh, Vacuum 157 (2018) 243-248.

[7] P. Haušild et al., Mater. Des. 31 (2010) 1821-1827. 
Edge 1
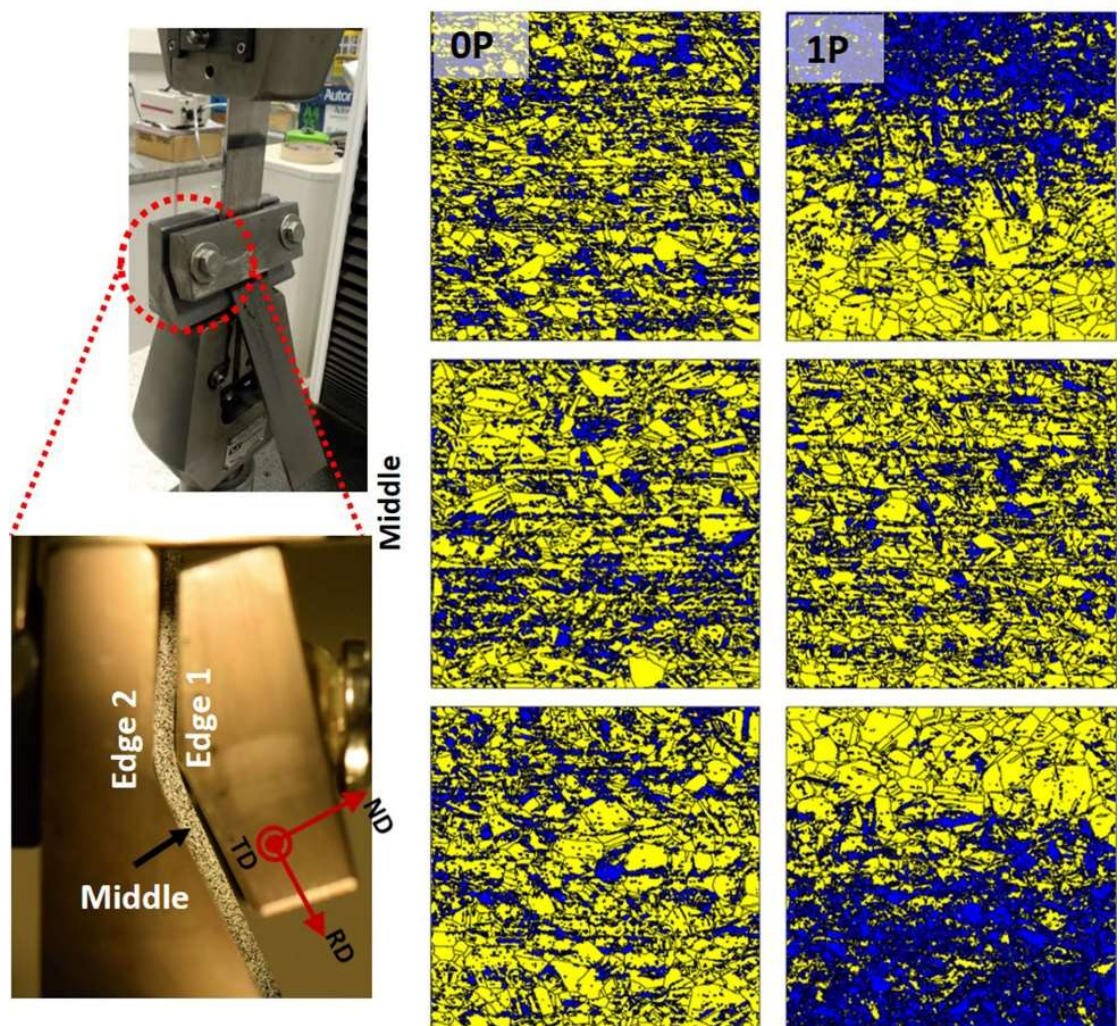

$200 \mu \mathrm{m}$

Edge 2

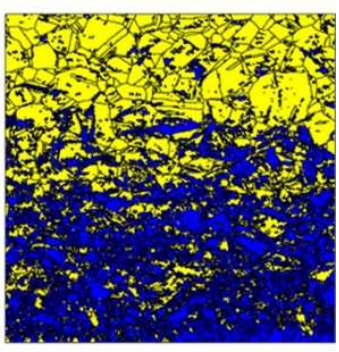

Iron bcc $\alpha^{\prime}$ Iron fcc $\gamma$

Figure 1. ECASE process scheme and microstructural evolution in different areas of the sheet thickness for both, initial (0P) and processed material by ECASE (1P).

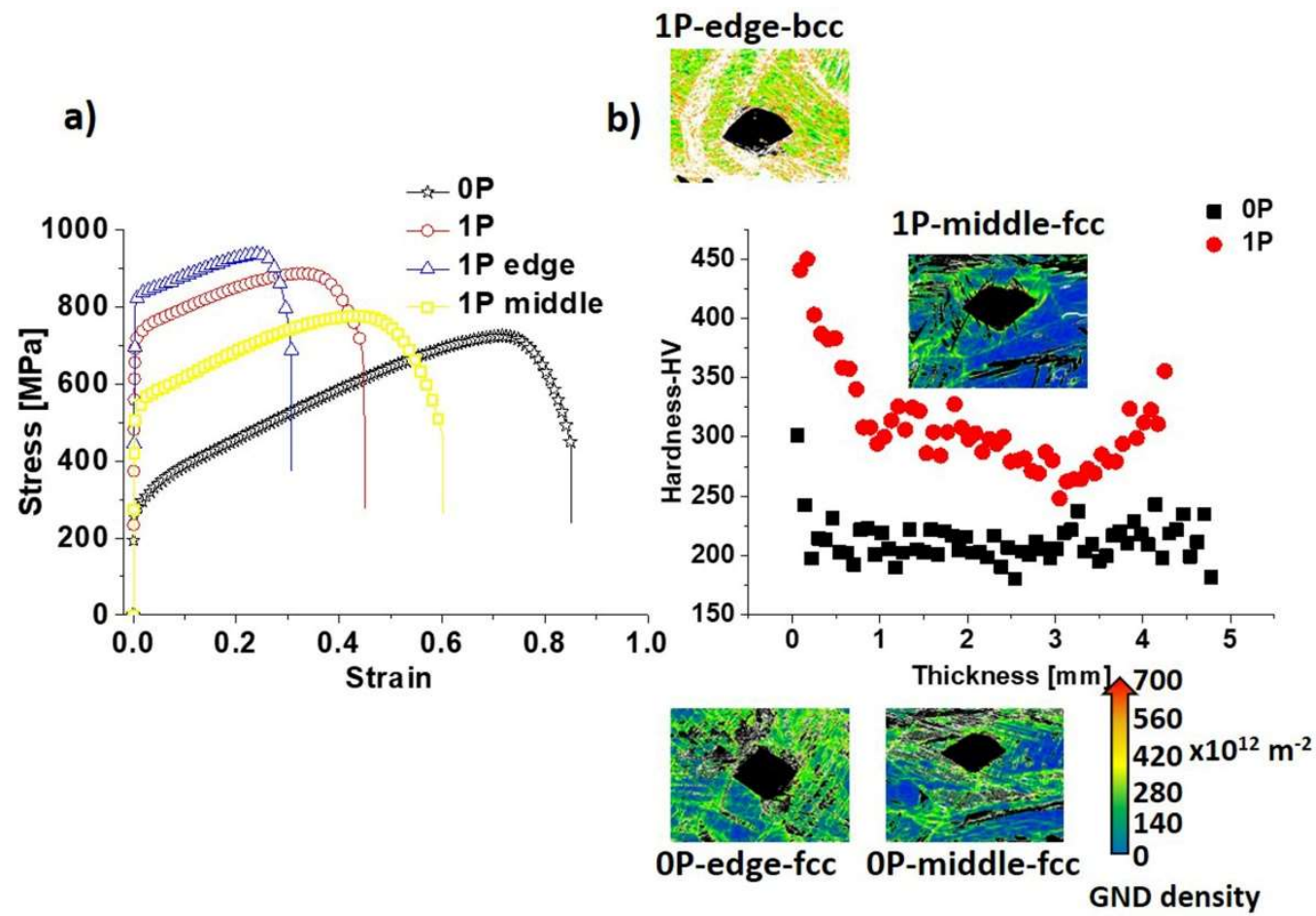

Figure 2. Mechanical and microstructural properties, a) tensile curves for different areas along the sheet thickness, b) hardness measurements together with the GND evolution for different areas across the sheet thickness. 